ISSN: 2664-8148 (Online)
Liberal Arts and Social Sciences
International Journal (LASSIJ)
https://doi.org/10.47264/idea.lassij/2.2.3
Vol. 2, No. 2, (July-December) 2018, 22-28
https://www.ideapublishers.org/lassij

\title{
Impact of Teacher's Attitudes on Academic Achievement of Students in Mathematics
}

\author{
Kaleem Ullah $^{1 *}$, Sareer Badshah ${ }^{2}$ and Hina Qamar ${ }^{1}$ \\ 1. Department of Statistics, Women University Swabi, Swabi Pakistan \\ 2. Department of Statistics, Islamia College-University Peshawar, Pakistan.
}

\begin{abstract}
This study is conducted to find out the factor related to teacher which may contribute to the students` achievement in mathematics. For this purpose, a sample of 605 students is collected from 14 departments of different educational institutions in Peshawar, Khyber Pakhtunkhwa. Furthermore, the data is collected from BS, $5^{\text {th }}$ semester except form department of mathematics. Data is analysed through the SPSS version 20. Data is subjected to statistical analysis using various statistical tools including descriptive statistic, t-test for independent sample, odd-ratio and binary logistic regression. Findings reveal that teaching method of the teacher has a significant impact, the value of teacher's attitude in the class is also highly significant, teacher delivery of lecture in understandable language value shows a significant impact on students achievement in Mathematics and teacher motivated in mathematics learning's value also shows the high significant result. The value of providing teaching material is also significant. Findings also shows that teachers take interactive class, adopt positive attitude, use understandable language, motivate and provide teaching material contribute to students`academic achievements.
\end{abstract}

Keywords: Mathematics Achievements, Teaching Effectiveness, Learning Motivation, Language and Teaching Material.

\section{Introduction}

Mathematics is considered the mother of all learning in both arts and sciences. It has indispensable importance in nearly all fields: angles in sports, measurement in the field of fashion, technology and economics etc. This perception of Mathematics has gained additional attention with the rapid development of information and communication. Mathematic is not simply a computation, but a tool for understanding social system, relationships and practices to find solution for complex real-life problems. Mathematics is requisite for people of all ages to be successful in life. Mathematics is a critical skill for all, who have good or poor grade. In today's changing world, its importance is increasing in terms of technological change (Burghes, 2011 \& Norris, 2012). The importance of Mathematics cannot be overemphasized in this epoch of science and technology. It is a terminology of science which provides a foundation for developing technology. If anyone doesn't recognise the terminology of science, how can he understand science or build up the applied sciences. That is why developed nations are concentrating too much on Mathematics. 
Despite the utility of mathematics in everyday life, there are components that adversely affect the students' ability to understand and apply mathematics concepts. Peshawar, a historical city of Khyber Pakhtunkhwa, Pakistan, is the centre of education of the province. Every year, it provides thousands of graduates to the job market. A growing body of research indicates a number of factors affecting the mathematics achievement of students. However, in this area there is no such study carried out. This study sought to define the mathematical achievements of students and related teachers` factors. The study helps the students to become mindful of the factors that affect their performance in mathematics. Knowing such factors can assist them identify their strengths and weaknesses that constantly interfere their performance in mathematics. This will, in turn, inspire the students to sweep over their weaknesses and hence, results to a good performance of students toward Mathematics. This study also provides teachers teaching mathematics with a better understanding of, and a deeper insight into the demand and problems of their students.

\section{Literature Review}

A study of 1876 respondents in secondary schools in the Baringo County in Kenya found that new and effective teaching method makes better learning environment and decrease learner differences. It also revealed that inadequate teaching/ learning material causes poor performance (Mbugua et al., 2012). A Report of the study of a sample of 20 secondary level students in Zimbabwe reveals that replacing traditional teaching methods by new methods enhances student's performance and decreases differences in the learners (Awoniyi, 2013). The analysis of the responses of a sample of 201 primary, high and secondary level students Libya showed that teaching method and students ' achievement is significantly positive related (AlAgil et al., 2012). Saritas and Akdemir (2009) have studied 250 participants of undergraduate students in a public university in Turkey. The study identified instructional strategies, methods and teacher competency in math education as the most effective factors in enhancing the academic performance of students. Olayiwola et al. (2011) have investigated a sample of 849 students in colleges of education, polytechnics and universities in Nigeria. Their analysis confirms that good teaching method has a positive impact on student academic achievement.

A study of a sample of 201 primary, high and secondary level students conducted in Libya, revealed that the attitude of teachers highly effects the academic performance of students (AlAgili, 2012). Similarly, another study of more than 8000 school level students in South Africa and this reported that teachers' attitude has direct effects on the achievements of students in mathematics (Howie, 2005). Wright and Nuthall (1970) in their study of a sample of 296 respondents in Christchurch city in New Zealand also found significant correlation between teacher behavior and students` performance. Ahmad et al. (2013) have found in a study of 291 students in Malaysia that native language plays a key role in better understanding of concepts and acquiring knowledge. Launio (2015) has conducted a study comprising of 58 high school students in Philippine, found that student learn more when taught bilingually. Broussard and Garrison (2004) have collected 241 samples from elementary-school-aged children at Southern United states, to examine the relationship between classroom motivation and academic achievement in mathematics. They found that a higher level of motivation was related to higher grades in math. A study consists of 200 students at school level in India indicated that motivation has significant relationship to academic performance (Siddiqi, 2014).

Mbugua et al. (2012) have studied 1876 students` respondent in secondary schools in Baringo County in Kenya, reported that lack of motivation causes poor performance. The results of a 
study consist of 3227 school level students in USA showed a positive effect of motivation on math achievement (Singh et al., 2002). Saritas \& Akdemir (2009) in their study of 250 undergraduate students in a public university Turkey, found that motivation or concentration as one of the most effective factors affecting academic achievement. Nonis and Hundson (2006) studied 288 undergraduate students in the United States, which showed that motivation has positive effect on the academic performance of students.

\section{Methods and Materials}

Different departments were selected from the Islamia College-University Peshawar, Superior Sciences College, Peshawar and Government College, Peshawar. Then from departments, class BS $\left(5^{\text {th }}\right)$ was selected, where mathematics was taught as a minor subject. Students of mathematics as major field was omitted because the researcher has interested in outcomes of mathematics as minor field. The three major educational institutions have been selected (i.e. Islamia College-University Peshawar, Government College Peshawar and Superior Science College Peshawar), because there was no BS program in other colleges in Peshawar. Whole class of BS $\left(5^{\text {th }}\right)$ semester was considered as a representative sample of the department. It is therefore suggested that the sample size of 940 students is fairly representative of the population. Data was collected from a cross-sectional of students i.e., B.S $5^{\text {th }}$ semester of 16 departments during the year 2016 by using stratified random sampling. These departments, including Botany, Chemistry, Computer Science, English, Economics, Electronics, LLB (Hons), LLB (Sharia), Management Sciences, Pakistan study, Psychology, Physics, Political Science, Statistics, Urdu and Zoology. The information collected is analysed by using SPSS version-20 and different Statistical techniques were used. Descriptive Statistics mean percentage and standard deviation; Two sample t-test for independent samples is used to compare the average GPA of students and teacher factors while Chi-square and odds ratio is used to compare its percentages in the GPA. Also, Binary logistic regression is applied for analysing the different factors of the study.

\section{Results and Discussion}

Table- 1 shows that there is a significant difference in the average GPA and teaching method of teachers ( $\mathrm{t}$-value $=3.117, \mathrm{P}$-value $=0.002$ ), where it is further indicated that in $<3 \mathrm{GPA}$ group, $15.8 \%$ interactive against $21.5 \%$ other teaching method (Chi-Square $=2.341, \mathrm{P}$-value $=0.126 \&$ O.R $=0.702,95 \%$ C.I is $0.445,1.106)$. There is a highly significant difference in average GPA of students in relation to teachers' attitude in class ( $\mathrm{t}$-value $=3.637$, P-value $=0.000$ ), where it is further noted that $17.7 \%$ teachers' attitude has positive as compare to $26.6 \%$ teachers' attitude has negative in <3 GPA group (Chi-Square $=2.722$, P-value $=0.099 \&$ O.R $=0.604$, 95\% C.I is $0.330,1.105)$.

There is a significant difference in average GPA of students upon understandable language during teaching ( $\mathrm{t}$-value $=2.515, \mathrm{P}$-value $=0.012$ ), while it is further indicated that in <3GPA group, $17.4 \%$ students who are taught in understandable language against $26.9 \%$ students who are not taught in understandable language $($ Chi-Square $=3.249, \mathrm{P}$-value $=0.071 \& \mathrm{O} . \mathrm{R}=0.583$, $95 \%$ C.I is $0.322,1.054)$. Significantly high difference is observed in average GPA of students whose teacher motivate them in Mathematics learning ( $\mathrm{t}$-value $=3.674$, P-value $=0.000)$, where it is further investigated that $16.8 \%$ students whose teacher motivate them as compare to $23.7 \%$ students whose teacher do not motivate them in <3GPA group (Chi-Square=2.733, Pvalue $=0.098 \&$ O. $R=0.658,95 \%$ C.I is $0.400,1.083$ ). There is significant difference in average 
GPA of students to whom teachers provide teaching material ( $\mathrm{t}$-value $=3.489, \mathrm{P}$-value $=0.007$ ), where it is further shown that in <3GPA group $14.6 \%$ yes against $25.1 \%$ no (Chi-Square $=8.423$, $\mathrm{P}$-value $=0.004 \&$ O.R $=0.520,95 \%$ C.I is $0.333,0.812$ ).

Mean GPA of teacher provides teaching material to student is higher than teacher does not provide teaching material to student. The percentage of teacher provides teaching material to student in <3GPA is less than percentage of teacher does not provide teaching material to student. The odds of teacher provide teaching material to student is 0.520 times less likely than teacher does not provide teaching material to students. Chi-Square reveals that there is highly significant association between Mathematics GPA and of teacher provides teaching material to student. When teacher provides teaching material to students, they may take help from it. Thus, they learn difficult topic easily.

Table-1: Comparing different Teacher Factors

\begin{tabular}{|c|c|c|c|c|c|c|c|c|c|c|c|}
\hline \multirow{2}{*}{ Factor } & \multirow{2}{*}{$\mathrm{N}$} & \multirow{2}{*}{$\%$} & \multirow{2}{*}{$\begin{array}{l}\text { Mean } \\
\text { GPA }\end{array}$} & \multirow{2}{*}{$\begin{array}{l}\text { St. } \\
\text { Dev. }\end{array}$} & \multirow{2}{*}{$\begin{array}{l}\text { t-value } \\
\text { P-value }\end{array}$} & \multicolumn{2}{|c|}{$<3 \mathrm{GPA}$} & \multicolumn{2}{|c|}{$\geq 3 \mathrm{GPA}$} & \multirow{2}{*}{$\begin{array}{c}\text { Chi- } \\
\text { Square } \\
\text { P-value }\end{array}$} & \multirow{2}{*}{$\begin{array}{c}\text { O.R } \\
(95 \% \text { C.I) }\end{array}$} \\
\hline & & & & & & $\mathrm{N}$ & $\%$ & $\mathrm{~N}$ & $\%$ & & \\
\hline \multicolumn{12}{|c|}{ Teaching method of teacher } \\
\hline Interactive & 304 & 60.3 & 3.45 & 0.540 & $3.117 * *$ & 48 & 15.8 & 255 & 84.5 & 2.341 & 0.702 \\
\hline Other & 200 & 39.7 & 3.28 & 0.648 & $(0.002)$ & 45 & 21.5 & 157 & 78.5 & $(0.126)$ & $\begin{array}{c}(0.445, \\
1.106)\end{array}$ \\
\hline \multicolumn{12}{|c|}{ Teacher attitude in the class } \\
\hline Positive & 451 & 87.6 & 3.41 & 0.572 & $3.637 * *$ & 80 & 17.7 & 371 & 82.3 & 2.722 & 0.604 \\
\hline Negative & 64 & 12.6 & 3.13 & 0.683 & $(0.000)$ & 17 & 26.6 & 47 & 63.4 & $(0.099)$ & $\begin{array}{c}(0.330 \\
1.105)\end{array}$ \\
\hline \multicolumn{12}{|c|}{ Teacher deliver lecture in understandable language } \\
\hline Yes & 447 & 87.0 & 3.41 & 0.565 & $2.515^{*}$ & 79 & 17.4 & 369 & 82.3 & 3.249 & 0.583 \\
\hline No & 68 & 13.0 & 3.21 & 0.744 & $(0.012)$ & 18 & 26.9 & 49 & 73.1 & $(0.071)$ & $\begin{array}{l}(0.522, \\
1.054)\end{array}$ \\
\hline \multicolumn{12}{|c|}{ Teacher motivate us in maths learning } \\
\hline Yes & 399 & 77.2 & 3.44 & 0.553 & $3.674 * *$ & 67 & 16.8 & 332 & 83.2 & 2.733 & 0.658 \\
\hline No & 118 & 32.8 & 3.21 & 0.675 & $(0.000)$ & 28 & 23.7 & 90 & 76.3 & $(0.098)$ & $\begin{array}{c}(0.400, \\
1.083)\end{array}$ \\
\hline \multicolumn{12}{|c|}{ Teacher provides teaching material } \\
\hline Yes & 322 & 62.4 & 3.45 & 0.544 & $3.489 * *$ & 47 & 14.6 & 275 & 85.6 & $8.423 * *$ & $0.520^{*}$ \\
\hline No & 195 & 37.6 & 3.27 & 0.648 & $(0.007)$ & 49 & 25.1 & 146 & 74.9 & $(0.004)$ & $\begin{array}{c}(0.333, \\
0.812)\end{array}$ \\
\hline \multicolumn{12}{|c|}{ Teacher explain every topic properly } \\
\hline Yes & 357 & 69.0 & 3.41 & 0.555 & 1.617 & 65 & 18.2 & 292 & 81.8 & 0.049 & 0.948 \\
\hline No & 161 & 31.0 & 3.32 & 0.665 & $(0.106)$ & 31 & 19.3 & 130 & 80.7 & $(0.825)$ & $\begin{array}{l}(0.590) \\
1.523)\end{array}$ \\
\hline \multicolumn{12}{|c|}{ Teacher encouraging questioning in class } \\
\hline Yes & 397 & 77.1 & 3.39 & 0.573 & 0.732 & 72 & 18.1 & 325 & 81.9 & 0.291 & 0.868 \\
\hline No & 117 & 22.9 & 3.35 & 0.653 & $(0.464)$ & 23 & 19.7 & 94 & 80.3 & $(0.590)$ & $\begin{array}{c}(0.518 \\
1.453)\end{array}$ \\
\hline
\end{tabular}

$*(p<0.05)$ and $* *(p<0.01)$ 
The average GPA of interactive teaching method of teacher is higher than other teaching methods of teacher, where this difference. Considerably, there is no significant difference in percentages between these groups. Positive attitude of the teacher in class has a positive effect on average GPA of the students than negative attitude of the teacher in class. There is significantly high difference in average GPA between these groups. When teacher attitude is positive in class student well get high GPA, as their percentage in <3GPA is less. When teacher deliver lecture in understandable language, students get high GPA than students whose teacher does not deliver lecture in understandable language. This difference is significant. When teacher delivers their lecture in understandable language, the student understands easily and quickly the topic.

Teacher motivate students in Mathematics learning, they achieve a high GPA on average compared to teacher does not motivate them. Teacher motivation encourages them and open their mind to learn subject. The difference between in average GPA of students explained every topic properly and students did not explain every topic properly is not significant. There is no effect of teacher who explains every topic properly or teacher does not explain every topic properly on Mathematics GPA. There is no big gap in mean GPA of teacher who encourage questioning in class and teacher do not encourage questioning in class.

\section{Logistic Regression Model of Teacher Factors:}

The equation of the line from the output given in table;

$$
\ln \left[\frac{\hat{p}(x)}{1-\hat{p}(x)}\right]=1.761-0.588 x_{1}
$$

For the model selection, 2 Log likelihood $=449.141$, Cox \& Snell R Square $=0.012$ and Nagelkerke R Square $=0.020$. The coefficient for the teaching material is -0.588 , when the teacher provides teaching material, the odd of Mathematics GPA increases by 0.556 times when other variables are controlled. Its effect is significant.

When teacher provides teaching material to student is 0.556 times as compared to teacher does not provide teaching material to student in <3GPA group. In other words, when teacher does not provide teaching material to student is 1.799 times against teacher provides teaching material student in $<3 \mathrm{GPA}$, which is approximately double. In Mathematics there are a lot of methods to solve a problem, which need more practice to learn. When teacher provides teaching material to student, they learn it easily.

Table-2: Parameter Estimate, Backward Selection Method

\begin{tabular}{|l|l|l|l|l|l|l|}
\hline & B & S.E. & Wald & Df & Sig. & Exp(B) \\
\hline Teacher provides teaching Material (yes) & -0.588 & 0.239 & 6.051 & 1 & 0.014 & 0.556 \\
\hline Constant & 1.761 & 0.163 & 116.435 & 1 & 0.000 & 5.818 \\
\hline
\end{tabular}

\section{Conclusion}

The list of factors which related to teacher and may contribute to students learning achievement 
may so long, but the findings show that there are few factors which affect student's achievement in mathematics. This study confirms some results of previous work which affect mathematics achievement of students, such as a teaching method, teacher attitude in class, medium of communication, motivation and teaching material. When a teacher applies the interactive teaching method, a positive attitude in class, deliver lecture in understandable language, motivate their students towards mathematics learning and offer teaching material to the them; then they get a higher GPA as compared to those students to whom such facilities are not provided. The strategy is suggested to improve the achievements in mathematics were grouped into the following areas, comprises of teaching method and teaching material, medium of communication, attitude and motivation. Findings prove that if this model is followed properly then a positive contribute takes place in the students' academic achievement. The study recommends that for better learning of students, the session should be interactive and there should be use of language which is understandable for all. Teacher's attitude should be positive toward student, and the teachers should permit students if they have any questions. The teacher should motivate them towards learning and Math teachers should use effective instruction that will enable the students perform better towards a mathematics subject.

\section{References}

Ahmad, R. R., Jaaman, S. H., Majid, N., \& Rambely, A. S. (2013). Challenges in teaching and learning mathematics in the transition to English medium. Research Advances in Educational Technologies, 146-149.

Aiken, J. R., Lewis, R. D., \& Mason, R. (1961). The effect of attitudes on performance in mathematics. Journal of Educational Psychology 52(1), 19-28.

Al-Agili, M. Z., Mamat, M. B., Abdullah, L., \& Maad, H. A., (2012). The factors influence students' achievement in mathematics: A case for Libyan's students. World Applied Sciences Journal 17(9), 1224-1230.

Awoniyi, A. S. (2013). Sheep and goat method of teaching: A potent strategy for improving the learning of mathematics. OMAN Chapter of Arabian Journal of Business and Management Review 2(6), 1-8.

Broussard, S. C., \& Garrison, M. E. B. (2004). The relationship between classroom motivation and academic achievement in elementary-school-aged children. Family and Consumer Sciences Research Journal 33(2), 106-120.

Cilasun. (2013). An analysis of academic performance: Could family income and medium of instruction be determinants? Sosyoekonomi 19(19), 112-127.

Howie, S. J. (2005). Contextual factors at the school and classroom level related to pupils' performance in mathematics in South Africa. Educational Research and Evaluation 11(2), 123-140.

Launio, R. M., (2015). Instructional medium and its effect on students' mathematics achievement. International Journal of Multidisciplinary and Current Research 3(1), 462-465.

Mbugua, Z. K., Kibet, K., Muthaa, G. M., \& Nkonke, G. R. (2012). Factors contributing to students' poor performance in mathematics at Kenya certificate of secondary education in Kenya: A Case of Baringo County, Kenya. American International Journal of Contemporary Research 2(6), 87-91.

Nonis, S. A., \& Hundson, G. I. (2006). Academic performance of college students: Influence of time spent studying \& working. Journal of Education for Business 81(3), 151-159. 
Olayiwola, O. M., Salawu, O. O, Oyenuga, I. F., Oyekunle, J. O., Ayansola, O. A., Olajide, J. T., \& Agboluaje, S. A. (2011). On Statistical Analysis of Impact of Socio Economics Factors on Students' Academic Performance. International Journal of Research and Reviews in Applied Science (IJRRAS), 8(3), 359-399.

Saritas, T., \& Akdemir, O. (2009). Identifying factors affecting the mathematics achievement of students for better instructional design. International Journal of Instructional Technology and Distance Learning 6(12), 21-36.

Siddiqi, S. (2014). Impact of achievement motivation upon academic achievement and socioeconomic status. International Journal of Research in Commerce, IT \& Management 4(4), 50-53.

Singh, K., Granville, M., \& Dika S. (2002). Mathematics and science achievement: Effects of motivation, interest, and academic engagement. The Journal of Educational Research 95(6), 323-332.

Wright, C. J., \& Nuthall, G. (1970). Relationships between teacher behaviours and pupil achievement in three experimental elementary science lessons. American Educational Research Journal 7(4), 477-491. 